\title{
The Effect of Internal Ignition Coil on Combustion Engine Performance
}

\author{
${ }^{1}$ Raid Anam Gaib, ${ }^{2}$ Ahmed Bassam Aziz and ${ }^{3}$ Ahmed Ibrahim Jaber Alzubaydy \\ ${ }^{1}$ College of Engineering and Electrical Power Engineering, University of Tromso (UiT), \\ Tromso, Norway \\ ${ }^{2}$ College of Engineering, Electrical Power and Machines, University of Mous1, Mousl, Iraq \\ ${ }^{3}$ College of Engineering, Electrical Power and Machines, University of Diyala, Diyala, Iraq
}

\begin{abstract}
All internal combustion engines are using spark ignition system; this system contain inductance converts low voltage to high voltage "thousand voltes". At this state the principles of system are the primary coil of ignition system has a heavy wire with few turns. The secondary winding consists thousand turns of small wire. Its mean the energy that stored in the magnetic field of core will be same as the energy which transformed from spark plug. This design will give spark reaches spark plug at limited times to ignite the fuel engine. This system is working at high efficiency. The ignition coil steps up $12 \mathrm{~V}$ battery to high voltage required in combustion engine to make the current jumping from low to high current at spark terminal. By used technical power electronic $4 \mathrm{MOSFET}$ as bridge making the EMF reach more than $25000 \mathrm{~V}$ in the modern ignition system high resistance is simulate and present in MATLAB (Simulink and code).
\end{abstract}

Key words: Engine coil, ignition system, spark plug, high voltage and power electronics, park terminal, efficiency

\section{INTRODUCTION}

All internal combustion engines used spark ignition system, this system converts low voltage to high voltage for short time period. The principle of this system is representing as:

- It working at high efficiency when speed engine low or high

- Producing spark at spark plug in short time

- This system has two types of wire think with primary and small thin in secondary side

The spark system engines convert the electrical current to spark plug in short time when the internal combustion engine needs burn the maximum (fuel and air) at end the pressure stork, each spark appears at the plug gap just as the plug gap the piston approaches top dead centre on the compression stroke when the engine is idling. At higher speed or during part throttle earlier in the cycle. The mixture thus has short time to burn and deliver power (Heywood, 1998). Three types used to produce electrical spark ignition:

- Electronic ignition system

- Magneto ignition system

- Battery ignition system
All this type working depending on mutual electromagnetic induction. The ignition system consists of the spark plug, one or more pulse transformers (typically called coils), timing control circuit and distribution apparatus that supply the high-voltage pulse to the correct cylinder. In order for the spark to be created in circuit, a high voltage pulse $10-25 \mathrm{kV}$ and more is supplied between the centre electrode and the ground. This voltage is required to generate spark on terminal by ignition system. This system illustrated in Fig. 1.

In this study, resonant converter is used to produce the required high voltage spark. Simulation of capacitor discharge ignition system and resonant converter-based ignition system are carried out in MATLAB and their performance is compared.

As show in Fig. 2, represented the modern ignition system, the high voltage pulse is required to produce the spark, achieved by switching the current through the primary circuit of the ignition coil. Traditional ignition systems have system of circuit breakers opening and closing at specified intervals (Joshi et al., 2015).

\section{MATERIALS AND METHODS}

Ignition coil: The ignition coil transformer or the step up the 6 or $12 \mathrm{~V} \mathrm{DC}$ battery to high voltage required make the current jump the spark plug gap the air fuel mixture

Corresponding Author: Raid Anam Gaib, College of Engineering and Electrical Power Engineering, University of Tromso (UiT), Tromso, Norway 


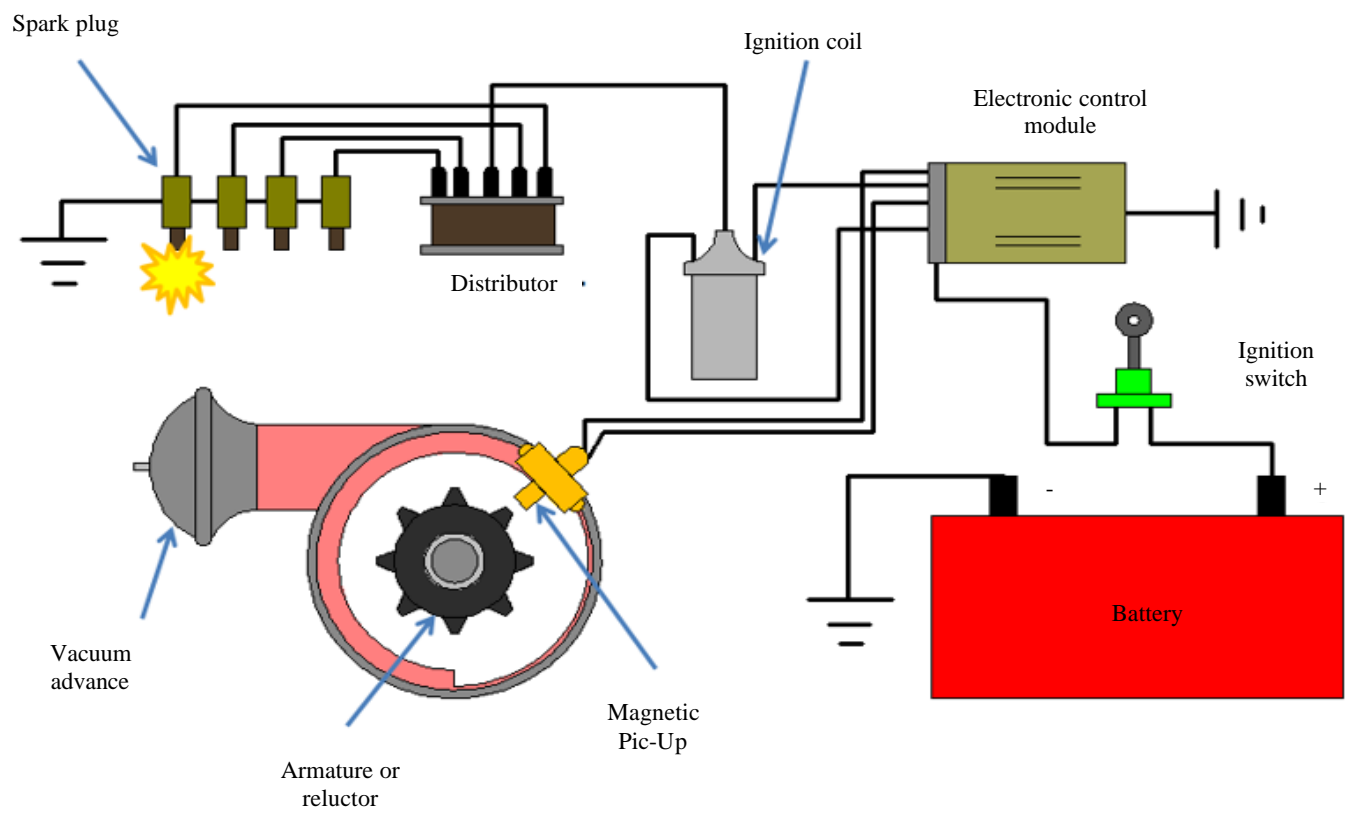

Fig. 1: Ignition system

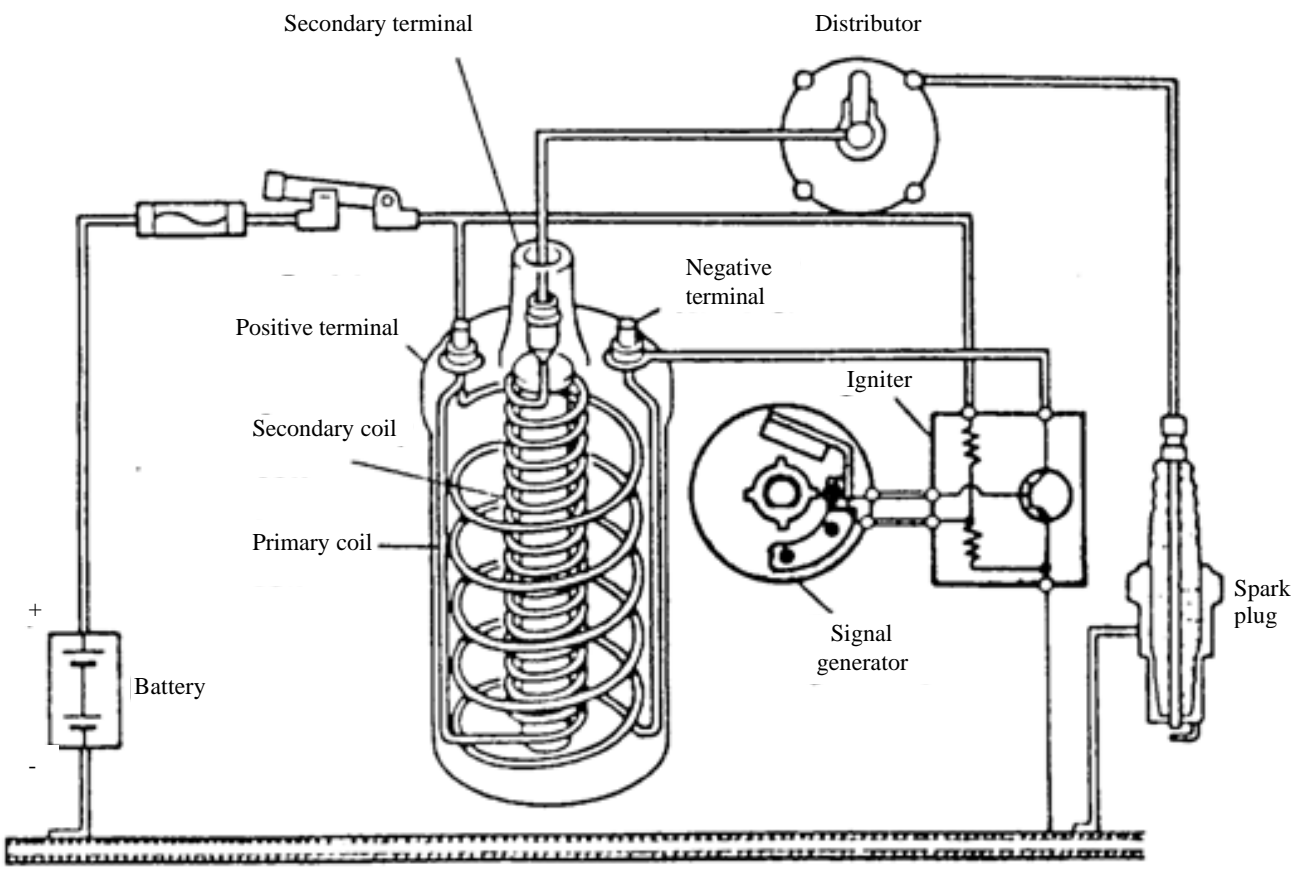

Fig. 2: Modern ignition system

between the two electrodes presents a high resistance to the passage of current. The voltage, pressure must be very high in order to push current the engine coil has two circuits a primary circuit and secondary circuit. The secondary circuit is made up of many thousands of turns of a find wire. The primary circuit is made up of a few hundred turns of heavier wire. The wire is wrapped or weld around the outside of the secondary winding. When the distributor contacts point close and current flows in the primary circuit a magnetic field builds up. When the distributor contacts point open and current stops flowing the magnetic field collapses (Domkundwar, 2001). The 
collapsing magnetic field induces high voltage in the secondary winding. This creates the high voltage surge that is contacted through the distributor rotor and cap to spark plug.

Battery ignition system theory: The ignition system distributor has two jobs. First, it closes and open the circuit between the battery and the ignition coil..

When the circuit close current flow in the ignition coil and builds up a magnetic field. When the circuit is open, the magnetic field in the coil collapses. The coil produces a high voltage surge to the correct spark plug at the correct instant dose this by means of the distributor rotor and cap and secondary winding. There are two basic types of distributor:

- First type is used contact point to close, open coil primary winding of the coil

- Second type using a magnetic block-up and a transistor control unit to interrupt the current flow of the coil primary circuit

\section{Consist of ignition system:}

- Battery ignition system

- Primary circuit

- Ignition switch

- Ignition coil

- Primary coil contact braked

- Secondary circuit

- Secondary coil

- Distributor cover

- Rotating part

- Spark plug

Theoretical parts: In this study calculate all parameters:

Where:

$$
\mathrm{E}=\frac{\mathrm{N}^{2} I \xi_{0} \zeta_{\mathrm{r}} \mathrm{A}}{\zeta} \cdot \frac{\mathrm{d}}{\mathrm{dt}}
$$

$$
\begin{aligned}
& \mathrm{E}=\text { Induced EMF } \\
& \mathrm{N}=\text { Number of turns in the coil } \\
& \mathrm{I}=\text { Maximum current in the coil } \\
& \zeta=\text { The permeability of the free space } 4 \pi \times 10^{-7} \zeta_{\mathrm{r}}= \\
& \\
& \zeta=\text { relative permeability } \\
& \mathrm{di}=\text { Rength of elongation } \\
& \mathrm{dt}=\text { Rate of change of current } \\
& \mathrm{A}=\text { Cross section area }
\end{aligned}
$$

\begin{tabular}{|c|c|c|c|c|c|c|c|}
\hline No. & $\mathrm{N}_{1}$ & $\mathrm{~N}_{2}$ & $\mathrm{I} / \mathrm{A}$ & $\mathrm{e}_{1} / \mathrm{V}$ & $\mathrm{e}_{2} / \mathrm{V}$ & $\varphi_{1 \text { iveb }}$ & $\varphi_{2 / \mathrm{rxeb}}$ \\
\hline 1 & 200 & 10000 & 0.2 & 10.048 & 502.4 & 1.0048 & 0.0502 \\
\hline 2 & 300 & 12000 & 0.6 & 67.82 & 2712 & $4.52 * 10^{3}$ & 0.1808 \\
\hline 3 & 400 & 14000 & 0.9 & 282 & 9034 & 0.0113 & 0.3617 \\
\hline 4 & 600 & 20000 & 1.2 & 542 & 18066 & 0.018 & 0.6028 \\
\hline
\end{tabular}$$
\text { Magnetic flux } \varphi=\frac{\mathrm{N}^{2} I \xi_{0} \zeta_{\mathrm{r}} \mathrm{A}}{\mathrm{d}}, \mathrm{V}_{1} / \mathrm{V}_{2}=\mathrm{N}_{1} / \mathrm{N}_{2}
$$

When $\mathrm{V}_{2}=\mathrm{E}_{2}$ EMF in secondary winding; $\mathrm{d}=$ Diameter of the coil, the result of the calculation shown in Table 1.

\section{RESULTS AND DISCUSSION}

Simulation: The ignition system has advantages over the inductive discharge system such as better performance of engine at high speed. However, the effect of number of turns on the secondary part coil produce induced EMF (Thipse, 2010). The relations between EMF in primary and secondary, The EMF with primary will be with flux and secondary will affect with number of turns. At lower speeds the ignition and high speed by using MATLAB Simulink (code) (Fig. 5-12). And result of modern ignition illustrated in Fig. 3.

Figure 4 the curve represented increases in EMF in secondary winding from $12 \mathrm{~V}_{\mathrm{DC}}$ to $11764 \mathrm{~V}$ when the number of turn ratio equal to 980/33 turn.

In this Fig. 5 can be seen when the change EMF thought the number of turns, the flux density is increasing. In this Fig. 6, increase in flux density when the number turns increases. Can see an increase in the magnetic flux in primary windings.

In this Fig. 7 by increase the number of primary winding. Will lead to increase in the magnetic flux where the induced current is growing which leads to an increase in the EMF.

In this Fig. 8 by increase the number of turns in the secondary windings can see an increase in the magnetic flux where the induced current is growing which leads to an increase in the EMF is very high. In this Fig. 9 and 10 represented a growth, the magnetic flux in the primary partition and the flux in the secondary part.

Figure 11 represented the relation between flux in the primary part of the coil and secondary part. When the Number of turns in primary and secondary windings ratio $=\mathrm{N} 2 / \mathrm{N} 1=980.333$ the $\mathrm{EMF}$ in secondary winding shown in Fig. 12.

Also, when the number of turns in primary and secondary windings ratio $=\mathrm{N} 2 / \mathrm{N} 1=1458.333$ shown in Fig. 13. When the number of turns in primary and secondary windings ratio $=\mathrm{N} 2 \mathrm{N1}=1941.666$, the $\mathrm{EMF}$ in secondary winding shown in Fig. 14. 


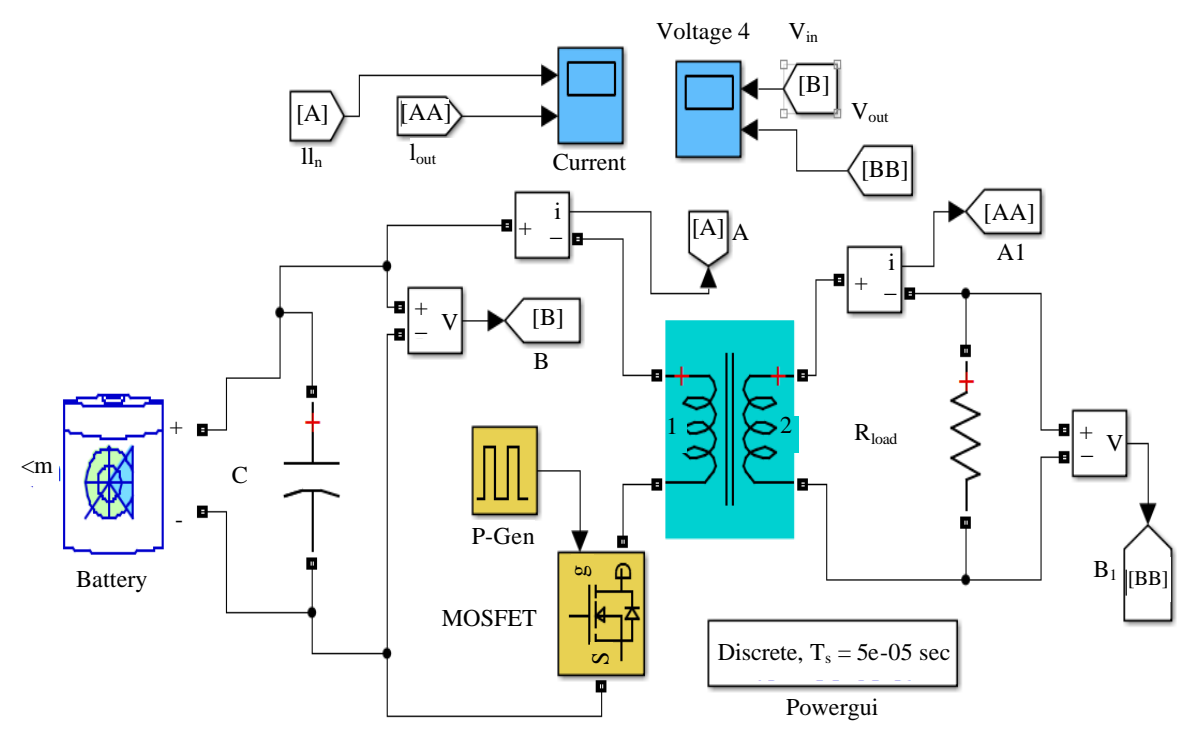

Fig. 3: Design ignition system by MATLAB

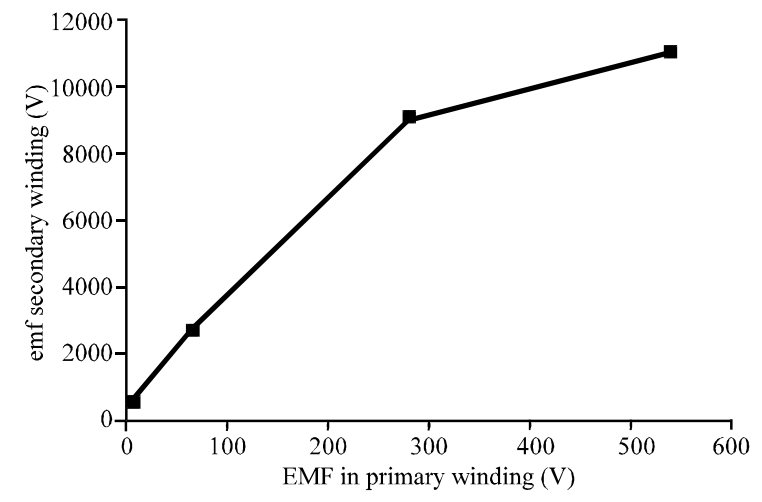

Fig. 4: Relation between EMF in primary and secondary winding in volt

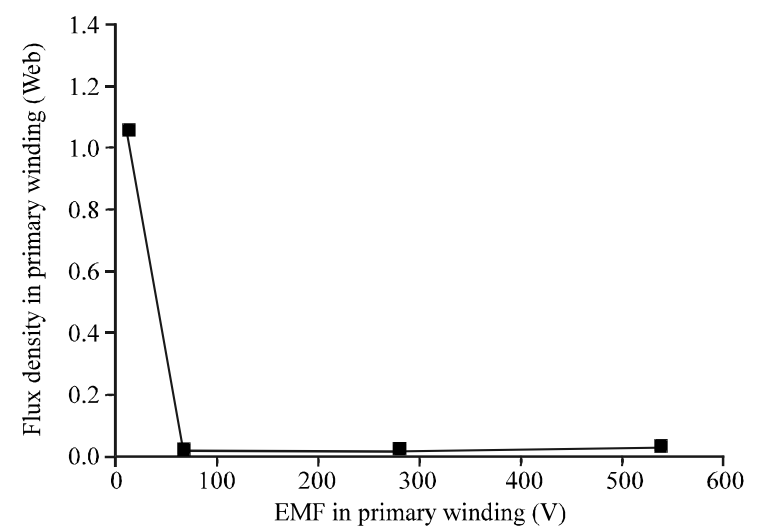

Fig. 5: Relation between EMF and flux in the primary winding

When the number of turns in primary and secondary windings ratio $=\mathrm{N}_{2} / \mathrm{N}_{1}=21300$ the EMF in secondary winding shown in Fig. 15.

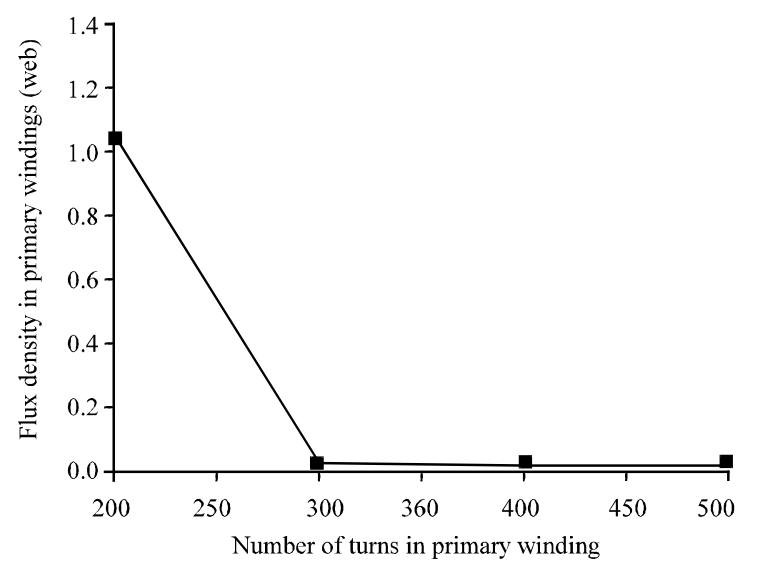

Fig. 6: The relation between flux and number of turns in primary windings

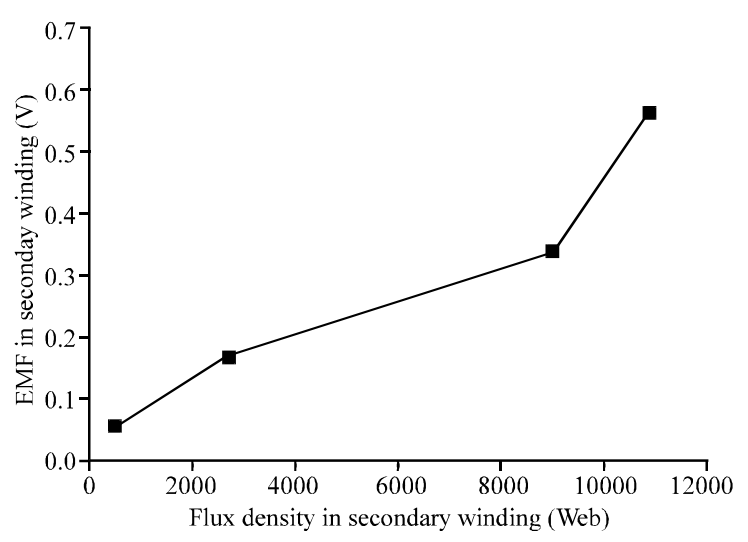

Fig. 7: The relation between EMF and number of turns in secondary windings 


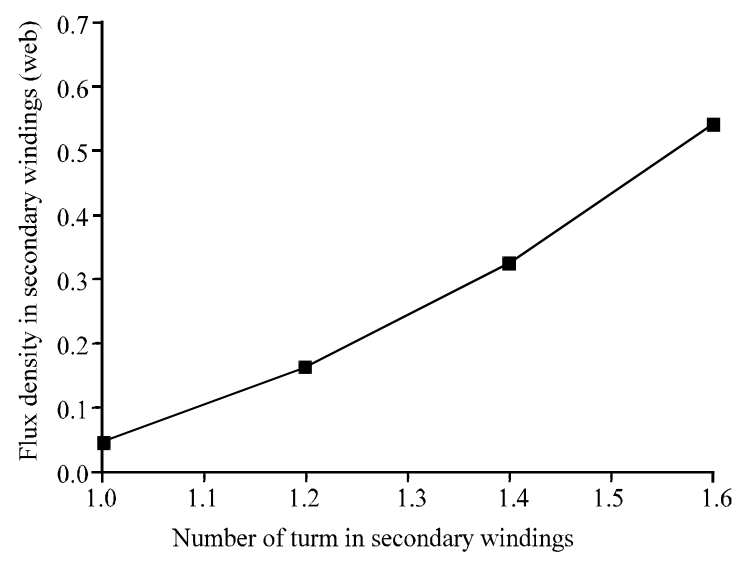

Fig. 8: The relation between flux and number of turn secondary winding

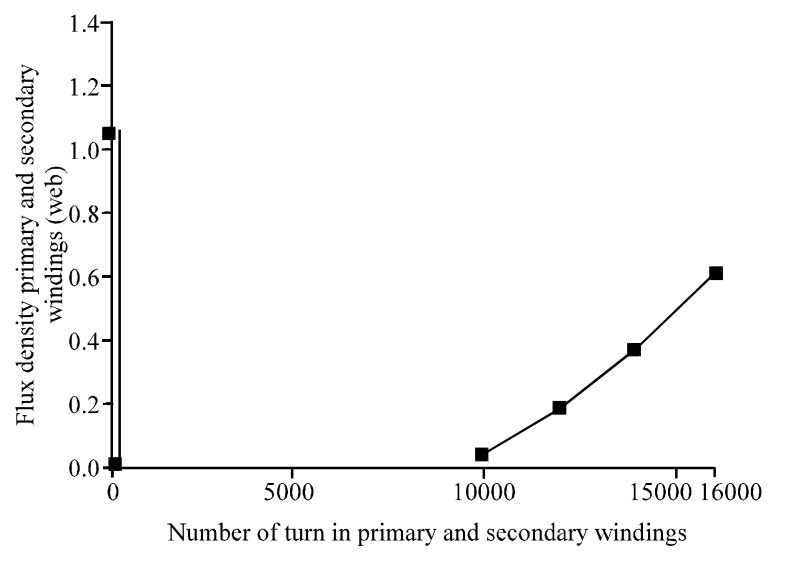

Fig. 9: The relation between flux and number of turns in primary and secondary windings

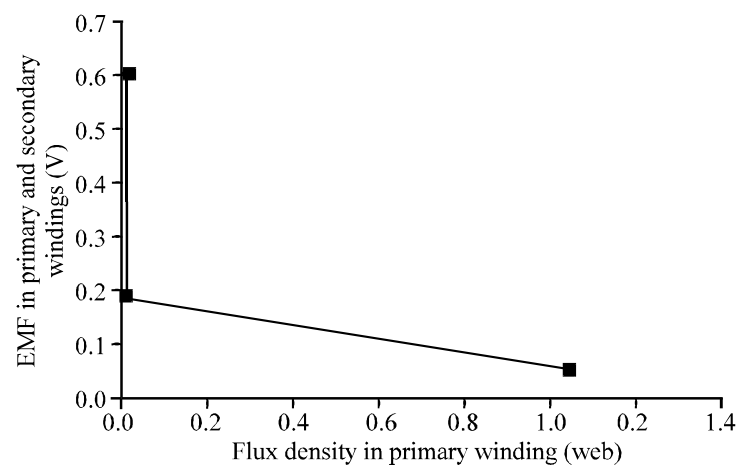

Fig. 10: The relation between flux in primary and secondary windings

The all cases of varying turn ratio in primary and secondary coil in the ignition system, the result of the high value of EMF shown in Fig. 16.

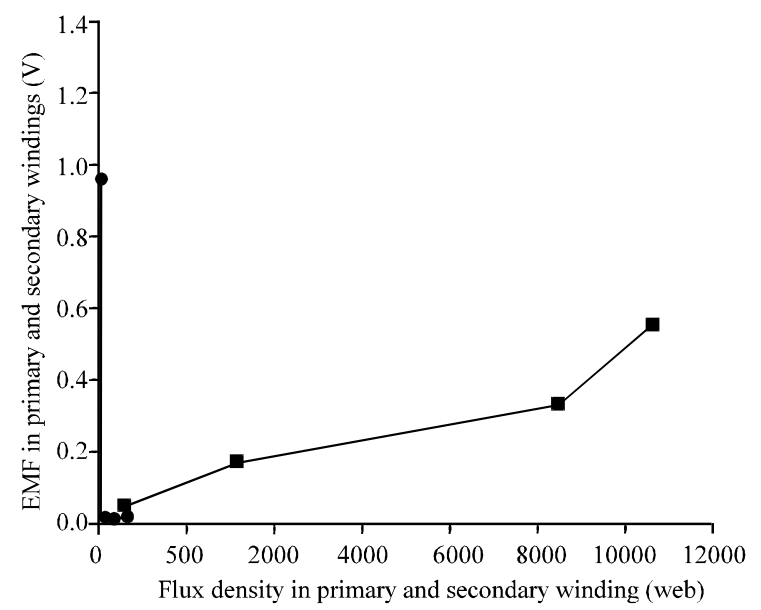

Fig. 11: The relation between, EMF and flux in primary and secondary windings

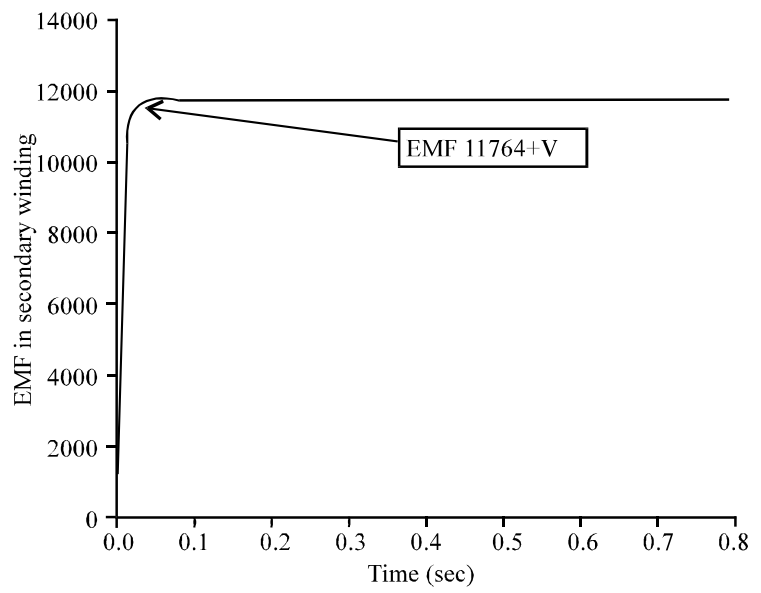

Fig. 12: The relation between EMF with time in secondary windings

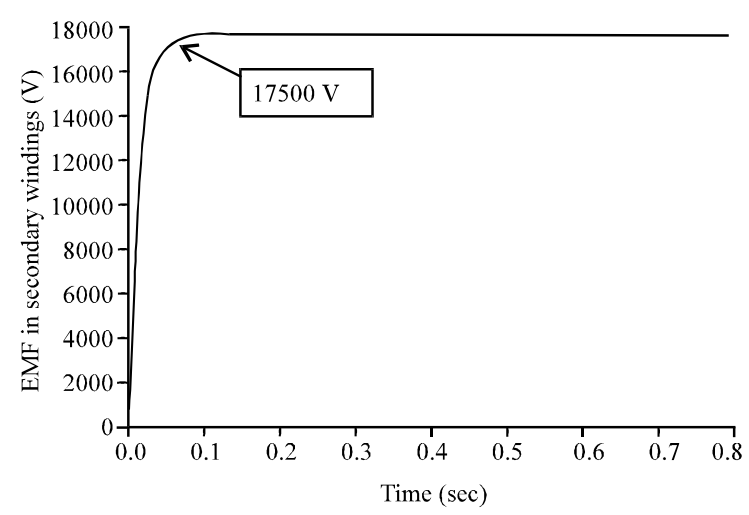

Fig. 13: The relation between EMF with time in secondary windings 


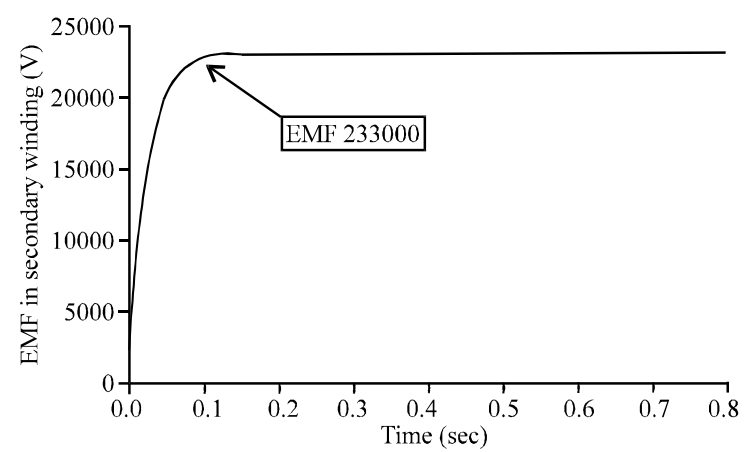

Fig. 14: The relation between EMF with time in secondary windings

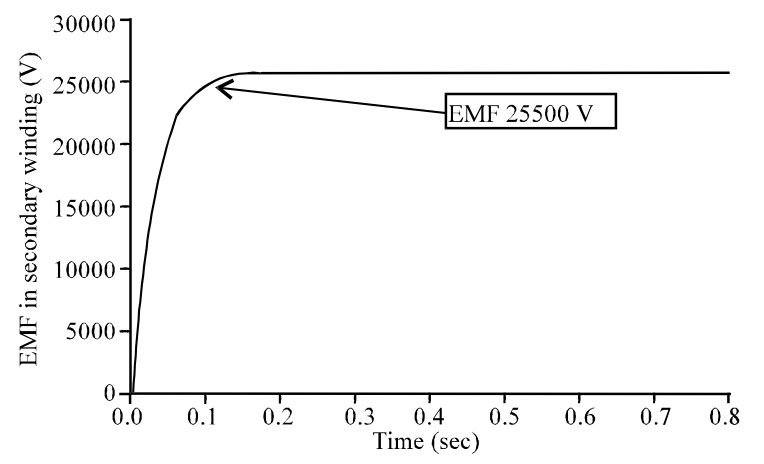

Fig. 15: The relation between EMF with time in secondary windings

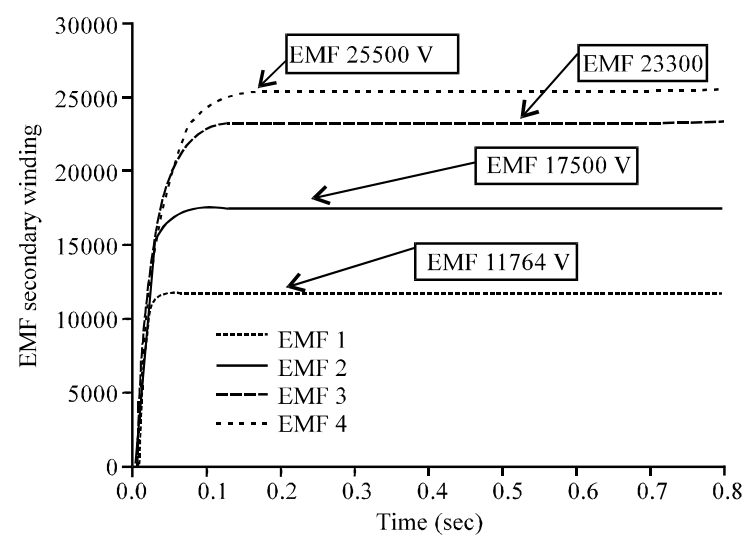

Fig. 16: The relation between all cases of EMF with time in secondary windings

\section{CONCLUSION}

The new design of combustion engine car in 20th century leading to develop and implement design for ignition system such as spark plug and improving new methods to get better performance for ignition system performance (Dave and Shaikh, 2013a, b).
The ignition system changing $12 \mathrm{~V}$ to high voltage reach more than $25000 \mathrm{~V}$. At this state the principles of system are produce and leading the spark to spark plug at limited times. This system is working at high efficiency, if the engine speed is high or low the ignition system will work and produce power in the change the number of turns in the secondary part of coil gate the relations between the flux, EMF and current in the primary and the secondary part of coil (Park et al., 2012; Rossetto et al., 2013; Porpatham et al., 2013).

The result in MATLAB Simulink the ignition coil steps up the $12 \mathrm{~V}$ battery to the high voltage required in engine to complete combustion. That mean the current jump at the spark plug gab to the air fuel maximum between the two electrodes present a high resistance to the passage of current.

\section{RECOMMENDATIONS}

Finally, this study will give idea for ignition system inductance coil and scop for internal power circuit producing high voltage thousand volt and in addition will help the researcher to modify the performance of coil ignition in the future.

\section{REFERENCES}

Dave, D.M. and M.A. Shaikh, 2013b. Effect of ignition parameters for enhancement of performance and emission of a four stroke single cylinder SI engine fuelled with $\mathrm{CNG}$ : A technical review. Intl. J. Eng. Res. Technol., 2: 2354-2358.

Dave, D.M. and M.A. Shaikh, 2013a. Optimization of ignition parameters for enhancement of performance and emissions of a four stroke single cylinder SI engine fuelled with CNG. Intl. J. Sci. Res. Dev., 1: 685-688.

Domkundwar, V.M., 2001. Internal Combustion Engines. Dhanpat Rai Publishing Company, Alandhar, India,

Heywood, J.B., 1998. Internal Combustion Engine Fundamentals. McGraw-Hill, New York.

Joshi, A.B., P.B. Umrigar, A.B. Patel, K.A. Patel and V.C. Patel, 2015. Effect of ignition energy on performance and emission of dedicated 4-Stroke single cylinder SI engine fuelled with biogas-an experimental investigation. Intl. J. Sci. Technol. Eng., 1: 391-399. 
Park, C., S. Park, C. Kim and S. Lee, 2012. Effects of EGR on performance of engines with spark gap projection and fueled by biogas-hydrogen blends. Intl. J. Hydrogen Energy, 37: 14640-14648.

Porpatham, E., A. Ramesh and B. Nagalingam, 2013. Effect of swirl on the performance and combustion of a biogas fuelled spark ignition engine. Energy Convers. Manage., 76: 463-471.
Rossetto, C., S.N.M. De Souza, R.F. Santo, J. De Souza and O.L. Klaus, 2013. Performance of an Otto cycle engine using biogas as fuel. Afr. J. Agric. Res., 8: 5607-5610.

Thipse, S.S., 2010. Alternative Fuels Concepts Technology and Developments. Jaico Publication, Mumbai, India,. 